\title{
Diabetes mellitus and risk of prostate cancer: a meta-analysis
}

\author{
S. Bonovas ${ }^{1,3} \cdot$ K. Filioussi $^{1} \cdot$ A. Tsantes ${ }^{2}$ \\ ${ }^{1}$ Department of General Practice, Athens General Hospital "G. Gennimatas", Athens, Greece \\ 2 Department of Internal Medicine, Athens General Hospital "G. Gennimatas", Athens, Greece \\ 3 Asklipiou 17-19, 15354 Glika Nera, Greece
}

\section{Abstract}

Aims/hypothesis. The association of diabetes mellitus with prostate cancer has been controversial. This study examines the strength of this association by conducting a detailed meta-analysis of the studies published in peer-reviewed literature on the subject.

Methods. A comprehensive search for articles published up to 2003 was performed, reviews of each study were conducted and data were abstracted. Prior to meta-analysis, the studies were evaluated for publication bias and heterogeneity. Pooled relative risk (RR) was calculated using the random- and the fixedeffects models. Subgroup and sensitivity analyses were also performed.

Results. We included 14 studies, published between 1971 and 2002, in the meta-analysis (five case-control studies, nine cohort studies). We found no evidence of publication bias $(p=0.89)$ or heterogeneity among the studies $(p=0.38)$. The association of diabetes with prostate cancer was statistically significant, both on the basis of a random-effects model ( $R R=0.91,95 \%$ CI: 0.86 to 0.96 ), and on the basis of a fixed-effects model ( $R R=0.91,95 \% \mathrm{CI}: 0.88$ to 0.94$)$. When the analysis was stratified into subgroups according to study design, the association was inverse in both cohort and case-control studies, but only in the former was it statistically significant. The sensitivity analysis strengthened our confidence in the validity of this association.

Conclusions/interpretation. Our meta-analysis findings provide strong evidence that people with diabetes have a significant decrease in risk of developing prostate cancer. There is biological evidence to support this association.

Keywords Diabetes mellitus · Epidemiology · Meta-analysis · Prostatic neoplasms

\section{Introduction}

Diabetes mellitus has been associated with an increased risk of several cancers, notably cancer of the pancreas, liver, biliary tract, endometrium, kidney and oesophagus $[1,2,3,4]$.

Received: 26 November 2003 / Accepted: 1 March 2004

Published online: 26 May 2004

(C) Springer-Verlag 2004

S. Bonovas (๘)

Asklipiou 17-19, 15354 Glika Nera, Greece

E-mail: sbonovas@med.uoa.gr

Tel.: +30-210-6040115

Abbreviations: $\mathrm{RR}$, relative risk
The association between diabetes and prostate cancer has been investigated by numerous epidemiological studies. The findings from these studies are inconsistent. Some report a lower risk of prostate cancer among men with diabetes compared to men without, while others found no or positive associations. Understanding the association between diabetes and prostate cancer has no doubt been hindered by the rarity of their co-occurrence in observational studies and the subsequent lack of statistical power to analyse this relationship adequately.

The overall aim of this study was to evaluate the strength of this controversial association, by conducting a detailed meta-analysis of the studies published on the subject in peer-reviewed literature. 


\section{Materials and methods}

Retrieval of published studies. To identify the studies of interest we conducted a computerised literature search. Sources included MEDLINE (from 1966 through to October 2003), OLDMEDLINE (from 1953 through to 1965) and EMBASE (from 1980 through to October 2003). Search terms included: "diabetes mellitus" or "diabetes" combined with "prostatic neoplasms" or "prostatic cancer" or "prostate neoplasms" or "prostate cancer". The titles and abstracts of studies identified in the computerised search were scanned to exclude any that were clearly irrelevant. The full text of the remaining articles was read to determine whether it contained information on the topic of interest. The reference lists of articles with information on the topic were reviewed to identify citations to other studies of the same topic. Reference lists of review articles were also reviewed to check that the assembled list of relevant publications was complete.

Inclusion and exclusion criteria. The studies considered in this meta-analysis were case-control, cohort or cross-sectional studies that evaluated diabetes mellitus and prostate cancer incidence and/or mortality.

Articles were excluded from the analyses for either or both of the following reasons: (i) they did not include diabetes as a risk factor for prostate cancer; (ii) there was insufficient published data to estimate relative risk (RR) or determine a confidence interval. In studies with multiple publications from the same cohort or population, only data from the most recent publication were included in the meta-analysis, with reference in the text to the older publications.

We did not assess the methodological quality of the primary studies, since quality scoring in meta-analysis of observational studies is controversial. Scores constructed in an ad hoc fashion may lack demonstrated validity, and results may not be associated with quality $[5,6,7]$. Instead, we performed subgroup and sensitivity analyses as is widely recommended [7, 8, 9]. Hence, no study was rejected because of methodological characteristics or any subjective quality criteria.

We included in this meta-analysis studies reporting different measures of relative risk (odds ratio, incidence rate ratio, standardised incidence ratio). In practice, the three measures of effect yield very similar estimates of relative risk, since prostate cancer is a rare occurrence.

Data extraction. Information from the studies was extracted by S. Bonovas and K. Filioussi, working independently. Standardised data-abstraction forms were used for this purpose. The following data were collected from each study: (i) publication data, first author's last name, year of publication, country of the population studied; (ii) study design; (iii) number of subjects; (iv) age of subjects; (v) relative risk and 95\% confidence intervals; (vi) case definition for prostate cancer; (vii) diabetes ascertainment; (viii) control for confounding factors by matching or adjustments. Information was not always provided for all of the above-named categories.

Inconsistencies were reviewed again until agreement was achieved.

In studies where more than one estimate of effect (RR) was presented, we chose the "most adjusted" estimate, i.e. the estimate adjusted for the largest number of potential confounders.

Statistical analysis. Two techniques were used to estimate the pooled relative risk estimates of these dichotomous factors: the Mantel-Haenszel method [10] for the assumption of a fixed-effects model, and the DerSimonian-Laird method [11] for the assumption of a random-effects model. The fixed-effects mod- el leads to valid inferences about the studies assembled, whereas the random-effects model assumes that the particular study samples were drawn from a larger universe of possible studies, and leads to inferences about all studies in that hypothetical population of studies. The random-effects approach often leads to wider confidence intervals. If heterogeneity is not present, the fixed-effects and the random-effects models provide similar results. When heterogeneity is found $(p<0.05)$, both models may be biased.

Publication bias was evaluated using the funnel graph, the Begg and Mazumdar adjusted-rank correlation test [12] and the Egger regression asymmetry test [13]. The Begg and Mazumdar test is a statistical analogue of the visual funnel graph. It determines whether there is a significant correlation between the effect estimates and their variances. The absence of a significant correlation suggests that the studies have been selected in an unbiased manner. The Egger regression asymmetry test tends to suggest the presence of a publication bias more frequently than the Begg approach. It detects funnel plot asymmetry by determining whether the intercept deviates significantly from zero in a regression of the standardised-effect estimates against their precision.

To evaluate whether the results of the studies were homogeneous, we used Cochran's $Q$ test [14]. It is a chi square test with degrees of freedom equal to the number of studies minus one, and is used to test the null hypothesis that the difference between the study estimates of relative risk is due to chance (the smaller the $p$ value, the less homogeneity present among study results).

Data were stratified into subgroups on the basis of study design. This was done to examine consistency across varying study designs with different potential biases. Homogeneity was assessed overall and within this stratification.

To evaluate the robustness of the results of this meta-analysis, we also performed a one-way sensitivity analysis. In this analysis, the overall homogeneity and effect size were calculated, removing one study at a time [15].

We also calculated the overall homogeneity and effect size excluding studies where diabetes was ascertained on the basis of a positive history alone.

Finally, to investigate the impact of the control for confounding factors on the study estimates of relative risk, we grouped the studies into two categories. The first category included studies with adequate control for potential confounders $(\geq 2)$, the second one included studies with poor control ( 0 or 1$)$.

STATA 6 software was used for the statistical analyses (STATA, College Station, Tex., USA).

For all tests, a probability level of less than 0.05 was considered statistically significant.

\section{Results}

Search results. The primary computerised literature search identified 233 records. Examination of these records yielded 47 potentially relevant manuscripts for further review. The full text was read and the reference lists were checked carefully. Finally, we identified 25 studies examining the association between diabetes and prostate cancer [16, 17, 18, 19, 20, 21, 22, $23,24,25,26,27,28,29,30,31,32,33,34,35,36$, $37,38,39,40]$.

Of these, eight studies [16, 17, 18, 19, 20, 21, 22, 23] did not provide sufficient data to estimate relative 
Table 1. Studies included in the meta-analysis

\begin{tabular}{|c|c|c|c|c|c|c|c|c|c|}
\hline Study & $\begin{array}{l}\text { Study } \\
\text { location }\end{array}$ & $\begin{array}{l}\text { Study } \\
\text { design }\end{array}$ & $\begin{array}{l}\text { All } \\
\text { subjects }\end{array}$ & $\begin{array}{l}\text { Subjects' } \\
\text { age }\end{array}$ & $\begin{array}{l}\mathrm{PC} \\
\text { cases }\end{array}$ & $\begin{array}{l}\text { Relative } \\
\text { risk }\end{array}$ & $95 \% \mathrm{CI}$ & $\begin{array}{l}\text { Control for } \\
\text { potential } \\
\text { confounders }^{b}\end{array}$ & Comments: \\
\hline $\begin{array}{l}\text { Tavani et al., } \\
2002 \text { [28] }\end{array}$ & $\begin{array}{l}\text { Italy \& } \\
\text { Greece }\end{array}$ & $\begin{array}{l}\text { Case- } \\
\text { control }\end{array}$ & 1616 & NA & 608 & 1.07 & $0.68-1.66$ & $1,4,5$ & $\begin{array}{l}\text { Combined data } \\
\text { from } 2 \text { case-control } \\
\text { studies }[25,26]\end{array}$ \\
\hline $\begin{array}{l}\text { Weiderpass et al., } \\
2002 \text { [29] }\end{array}$ & Sweden & $\begin{array}{l}\text { Cohort of } \\
\text { DM patients }\end{array}$ & 135950 & 61.7 & 2455 & 0.91 & $0.87-0.94$ & 1 & $\begin{array}{l}\text { Incident cases; } \\
\text { excluded cases } \\
\text { diagnosed within } \\
1 \text { year of diagnosis } \\
\text { of DM }\end{array}$ \\
\hline $\begin{array}{l}\text { Will et al., } \\
1999 \text { [30] }\end{array}$ & USA & Cohort & 305065 & $\geq 30$ & 2523 & 1.13 & $0.88-1.45$ & 1 & Incident cases \\
\hline $\begin{array}{l}\text { Wideroff et al., } \\
1997 \text { [32] }\end{array}$ & Denmark & $\begin{array}{l}\text { Cohort of } \\
\text { DM patients }\end{array}$ & 54571 & 64 & 505 & 0.9 & $0.8-1.0$ & 1,8 & $\begin{array}{l}\text { Incident cases; } \\
\text { excluded cases } \\
\text { diagnosed within } \\
1 \text { year of cohort entry }\end{array}$ \\
\hline $\begin{array}{l}\text { Coughlin et al., } \\
1996[33]\end{array}$ & USA & Cohort & 320909 & $35-57$ & 760 & 0.77 & $0.43-1.36$ & $\begin{array}{l}1,2,9,10, \\
11\end{array}$ & $\begin{array}{l}\text { Prostate cancer } \\
\text { deaths }\end{array}$ \\
\hline $\begin{array}{l}\text { Steenland et al., } \\
1995 \text { [34] }\end{array}$ & USA & Cohort & NA & $25-74$ & 156 & 1.45 & $0.78-2.71$ & $\begin{array}{l}1,5,9,10 \\
12,13\end{array}$ & $\begin{array}{l}\text { Incident cases and } \\
\text { deaths }\end{array}$ \\
\hline $\begin{array}{l}\text { La Vecchia et al., } \\
1994 \text { [35] }\end{array}$ & Italy & $\begin{array}{l}\text { Case- } \\
\text { control }\end{array}$ & 3258 & $<75$ & 125 & 0.7 & $0.3-1.6$ & 1 & \\
\hline $\begin{array}{l}\text { Smith et al., } \\
1992 \text { [36] }\end{array}$ & England & Cohort & 18274 & $40-64$ & 90 & 0.78 & $0.11-5.83$ & 1 & $\begin{array}{l}\text { Prostate cancer } \\
\text { deaths }\end{array}$ \\
\hline $\begin{array}{l}\text { Ragozzino et al., } \\
1982 \text { [39] }\end{array}$ & USA & $\begin{array}{l}\text { Cohort of } \\
\text { DM patients }\end{array}$ & NA & NA & 9 & 1.2 & $0.5-2.2$ & 1 & $\begin{array}{l}\text { Incident cases and } \\
\text { deaths; excluded } \\
\text { cases diagnosed within } \\
1 \text { year of diagnosis } \\
\text { of DM }\end{array}$ \\
\hline $\begin{array}{l}\text { Wynder et al., } \\
1971[40]\end{array}$ & USA & $\begin{array}{l}\text { Case- } \\
\text { control }\end{array}$ & 700 & $35-59$ & 300 & $1.18^{\mathrm{c}}$ & $0.66-2.13^{\mathrm{c}}$ & - & $\begin{array}{l}\text { Excluded cases } \\
\text { diagnosed within } \\
2 \text { years of diagnosis } \\
\text { of DM }\end{array}$ \\
\hline
\end{tabular}

DM, diabetes mellitus; NA, information was not available; PC, prostate cancer. ${ }^{a}$ Numbers in square brackets: reference citations. ${ }^{\mathrm{b}} 1$, age; 2 , race; 3 , coronary heart disease; 4 , education; 5, BMI; 6, vasectomy; 7, energy/fat/calcium/fructose/lycopene

risk or determine a confidence interval. They were excluded from the meta-analysis. We did not contact the prime investigators of these studies, as this would have been fruitless, given the average time (42 years, range: 18 to 71 years) since publication of these eight studies.

Two case-control studies $[25,26]$ were excluded from the meta-analysis due to the rule for multiple pu- intakes; 8, obesity; 9, income; 10 , cigarette smoking; 11 , serum cholesterol; 12, alcohol; 13, physical activity; 14, systolic blood pressure. ${ }^{c}$ Estimated from the raw data presented in the study report

blications from the same population. Their data had been included in a combined analysis [28], in order to assess in a larger data set the relation between diabetes and prostate cancer risk.

Two other case-control studies $[38,40]$ did not report relative risk estimates. However, they provided raw data needed to complete a $2 \times 2$ table and calculate 
unadjusted estimates of relative risk and 95\% confidence intervals. These studies were included in the meta-analysis.

Finally, we excluded one cohort study of diabetic patients [24] because the data from the study cohort were re-analysed and published later upon completion of 10 additional years of follow-up [29].

The remaining fourteen studies $[27,28,29,30,31$, $32,33,34,35,36,37,38,39,40]$ were included in the meta-analysis. Of these, five were case-control studies $[27,28,35,38,40]$, six were cohort studies [30, 31, $33,34,36,37]$ and the remaining three were cohort studies of diabetic patients [29, 32, 39]. Eight studies $[27,29,31,32,33,35,36,37]$ reported relative risks lower than 1 and six studies [28, 30, 34, 38, 39, 40] reported relative risks higher than 1 . Only two studies reporting relative risks lower than 1 and none reporting relative risks higher than 1 had confidence intervals that did not include unity [29, 31].

In eight of fourteen studies [27, 28, 30, 34, 35, 37, $38,40]$ diabetes was ascertained on the basis of a positive history alone.

Prostate cancer cases diagnosed within one year after diagnosis of diabetes had been excluded from the statistical analysis in five studies [29, 32, 37, 39, 40].

Twelve out of fourteen studies [27, 28, 29, 30, 31, $32,33,34,35,36,37,39]$ were controlled for potential confounders (at least for age).

Two studies did not indicate race [36, 39], but the majority of studies enrolled predominantly white participants $[27,28,29,30,31,32,33,34,35,37,38$, 40].

The majority of the studies were conducted in the United States [27, 30, 31, 33, 34, 37, 38, 39, 40], but some were carried out in the United Kingdom [36], and Europe [28, 29, 32, 35].

The publication dates of the studies included in the meta-analysis ranged from 1971 to 2002. Study designs, along with the estimated relative risks and $95 \%$ CIs are shown in Table 1.

Meta-analysis. The funnel plot had the expected funnel shape (Fig. 1). The $p$ values for the Begg and Mazumdar test and Egger test were $p=0.96$ and $p=0.89$ respectively, both suggesting a low probability of publication bias.

Similarly, the Cochran's $Q$ test had a $p$ value of $p=0.38(Q=13.85$ on 13 degrees of freedom), indicating that the results of the studies were homogeneous.

The statistical analysis revealed an inverse association between diabetes mellitus and prostate cancer. This association was statistically significant both in a fixed-effects model $(\mathrm{RR}=0.91,95 \% \mathrm{CI}: 0.88$ to 0.94 , $n=14)$, and in a random-effects model $(\mathrm{RR}=0.91,95 \%$ CI: 0.86 to $0.96, n=14)$.

Figure 2 illustrates the relative risks and 95\% CIs from the individual studies and the pooled results.

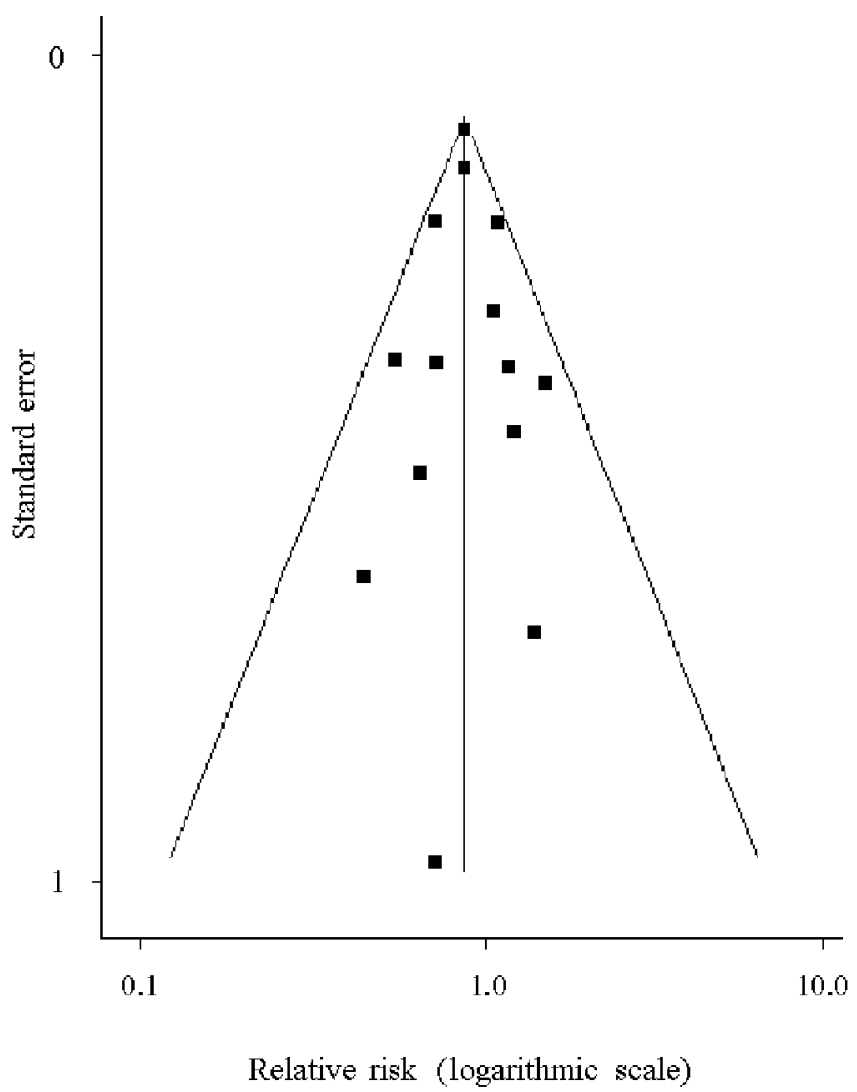

Fig. 1. Funnel plot of the relative risk of developing prostate cancer, according to the standard error for all studies (black squares) included in the meta-analysis. Relative risks are displayed on a logarithmic scale. $p=0.96$ for the Begg-Mazumdar test; $p=0.89$ for the Egger test

Subgroup and sensitivity analyses. To examine consistency across varying study designs with different potential biases, we stratified data into subgroups on the basis of study design. The inverse association was statistically significant among the cohort studies (random-effects model: $\mathrm{RR}=0.91,95 \% \mathrm{CI}$ : 0.85 to 0.98 , $n=9, p=0.29$ for homogeneity), but not among the case-control studies (random-effects model: $\mathrm{RR}=0.92$, 95\% CI: 0.70 to $1.22, n=5, p=0.39$ for homogeneity) (Table 2).

In the sensitivity analysis, the overall homogeneity and effect size were calculated, removing one study at a time. This analysis confirmed the stability of the inverse association between diabetes and prostate cancer (Table 3). It is interesting that even when excluding the study of Weiderpass et al. [29] from the analysis (this was the study that clearly carries most weight), the estimated pooled relative risk did not change at all ( $\mathrm{RR}=0.91,95 \%$ CI: 0.84 to $0.99, n=13$ ).

When the studies where diabetes was ascertained by history alone $[27,28,30,34,35,37,38,40]$ were excluded from the analysis, the $p$ value for the $Q$ test increased to 0.65 and the calculated effect estimate was identical in both a fixed- and a random-effects model (RR=0.90, 95\% CI: 0.87 to $0.94, n=6)$. 
Rosenberg et al., 2002

Tavani et al., 2002

Weiderpass et al., 2002

Will et al., 1999

Giovannucci et al., 1998

Wideroff et al., 1997

Coughlin et al., 1996

Steenland et al., 1995

La Vecchia et al., 1994

Smith et al., 1992

Thompson et al., 1989

Checkoway et al., 1987

Ragozzino et al., 1982

Wynder et al., 1971

Fixed-effects model: pooled estimate

Random-effects model: pooled estimate

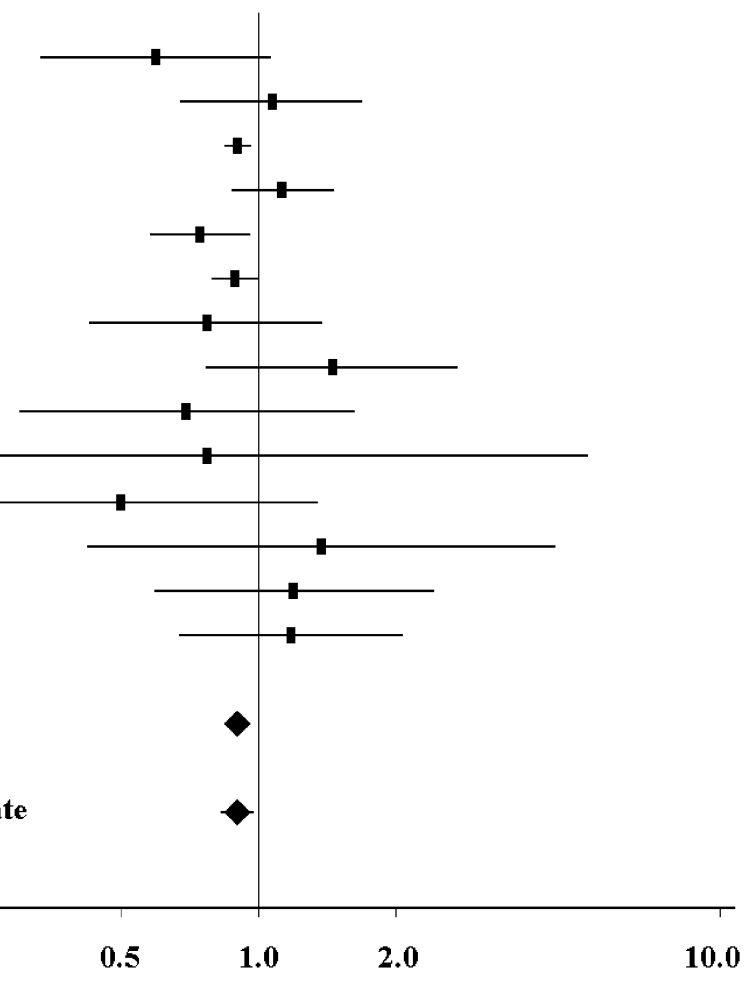

Relative risk (logarithmic scale)

Fig. 2. Analysis of studies, denoted by first author and publication year, that examined prostate cancer and its association with diabetes mellitus. The relative risk and 95\% CI for each study, along with the pooled estimates, are displayed on a logarithmic scale. For all studies, there is a statistically significant $9 \%$ decrease in the risk of developing prostate cancer among diabetic patients

Finally, when we investigated the impact of the control for confounding factors on the study estimates of relative risk, we observed that studies with adequate control for potential confounders $(\geq 2)$ appeared to have lower relative risk estimates than studies with poor control. Specifically, when we only included studies with adequate control for potential confounders $(\geq 2)$ in the meta-analysis, the random-effects model provided the following results $(\mathrm{RR}=0.86,95 \% \mathrm{CI}: 0.73$ to $0.99, n=7)$. In contrast, when only the studies with poor control for potential confounders ( 0 or 1$)$ were in-
Table 3. One-way sensitivity analysis

\begin{tabular}{lll}
\hline Study excluded & \multicolumn{2}{l}{ Fixed-effects model } \\
\cline { 2 - 3 } & OR & $(95 \% \mathrm{CI})$ \\
\hline None & 0.91 & $(0.88-0.94)$ \\
Rosenberg et al. [27] & 0.91 & $(0.88-0.94)$ \\
Tavani et al. [28] & 0.91 & $(0.88-0.94)$ \\
Weiderpass et al. [29] & 0.91 & $(0.84-0.99)$ \\
Will et al. [30] & 0.91 & $(0.87-0.94)$ \\
Giovannucci et al. [31] & 0.91 & $(0.88-0.95)$ \\
Wideroff et al. [32] & 0.91 & $(0.88-0.95)$ \\
Coughlin et al. [33] & 0.91 & $(0.88-0.95)$ \\
Steenland et al. [34] & 0.91 & $(0.88-0.94)$ \\
La Vecchia et al. [35] & 0.91 & $(0.88-0.94)$ \\
Smith et al. [36] & 0.91 & $(0.88-0.94)$ \\
Thompson et al. [37] & 0.91 & $(0.88-0.94)$ \\
Checkoway et al. [38] & 0.91 & $(0.88-0.94)$ \\
Ragozzino et al. [39] & 0.91 & $(0.88-0.94)$ \\
Wynder et al. [40] & 0.91 & $(0.88-0.94)$ \\
\hline
\end{tabular}

OR, odds ratio

Table 2. Pooled relative risk estimates for prostate cancer and diabetes mellitus by study design

\begin{tabular}{|c|c|c|c|c|c|c|}
\hline \multirow[t]{2}{*}{ Study type } & \multirow[t]{2}{*}{$n$} & \multicolumn{2}{|c|}{ Fixed-effects model } & \multirow{2}{*}{$\begin{array}{l}\text { Homogeneity, } \\
p \text { value }\end{array}$} & \multicolumn{2}{|c|}{ Random-effects model } \\
\hline & & $\mathrm{RR}$ & $95 \% \mathrm{CI}$ & & $\mathrm{RR}$ & $95 \% \mathrm{CI}$ \\
\hline All & 14 & 0.91 & $(0.88-0.94)$ & 0.38 & 0.91 & $(0.86-0.96)$ \\
\hline Case-control & 5 & 0.92 & $(0.70-1.22)$ & 0.39 & 0.92 & $(0.70-1.22)$ \\
\hline Cohort & 9 & 0.91 & $(0.88-0.94)$ & 0.29 & 0.91 & $(0.85-0.98)$ \\
\hline
\end{tabular}

$\mathrm{RR}$, relative risk 
cluded in the meta-analysis, the effect estimate was higher ( $\mathrm{RR}=0.92,95 \% \mathrm{CI}: 0.88$ to $0.95, n=7$ ).

\section{Discussion}

To the best of our knowledge, this is the first metaanalysis of published studies to evaluate the association between diabetes mellitus and prostate cancer. It shows that diabetic patients have a statistically significant $9 \%$ decrease in risk of developing carcinoma of the prostate.

When meta-analysis of observational data is performed, consideration of study bias is critical [7]. Existence of a bias in favour of publication of statistically significant results is well documented in the literature [41, 42, 43]. In addition, some epidemiological studies do not report relative risk estimates if variables under study are not significant at the initial "screening" stage. Such studies may therefore have been excluded from this meta-analysis. However, the likelihood of an important selection or publication bias in our results is low. We did not exclude any article during the identification and selection process, and both the Begg and Mazumdar test and the Egger test revealed no relation between the estimate of relative risk and study size ( $p=0.96$ and $p=0.89$ respectively). So, we are confident that important publication bias due to preferential publication of large studies with significant findings is unlikely to have occurred.

Similarly, the Cochran's $Q$ test had a $p$ value of $p=0.38$, indicating that the results of the studies were homogeneous. Moreover, the sensitivity and subgroup analyses strengthened our confidence in the validity of the overall conclusion that diabetic patients are at decreased risk of prostate cancer.

Nevertheless, our study has several limitations. The main limitation is lack of data on type of diabetes (Type 1 or Type 2) in the populations studied. A second potential limitation is that several of the studies we analysed had enrolled predominantly white participants. This is a concern, given the higher incidence of prostate cancer in black people [44, 45]. A third limitation is the possible diagnostic detection bias that is likely to have occurred in some of the primary studies included in the meta-analysis. It is well known that the prevalence of preclinical prostate cancer is high among older men (0.1-7.6\%) [46]. Increased monitoring of individuals recently diagnosed with diabetes could result in an increased detection of prostate cancers (detection bias). If such bias exists in the primary studies, it would imply that the $9 \%$ reduction in prostate cancer risk among diabetic patients, as shown in our meta-analysis, is underestimated. However, prostate cancer cases diagnosed within one year of diagnosis of diabetes were excluded from the statistical analysis in five primary studies $[29,32,37,39,40]$. This fact decreases the extent of the potential problem.
Another limitation is that non-differential misclassification of exposure to diabetes is likely to have occurred in the eight primary studies where diabetes was ascertained on the basis of positive history alone [27, 28, 30, $34,35,37,38,40]$. Since diabetes is an under-diagnosed condition, this may have caused non-differential misclassification to bias the results of the eight primary studies towards the null (relative risk $=1.0$ ). However, if such a bias exists, it would imply that the reduction in prostate cancer risk among diabetic patients, as shown in our meta-analysis, is once again an underestimate.

Although the epidemiological data currently available suggest that diabetic patients are at a significantly decreased risk of developing carcinoma of the prostate, our knowledge of the mechanisms underlying this association is incomplete. It is possible that, some factor may increase the risk of diabetes and at the same time decrease the risk of prostate cancer. Alternatively, this inverse relation may be a result of metabolic and hormonal aberrations associated with diabetes. The most obvious change in diabetic patients is a reduced insulin response. In vitro, insulin appears to be a growth factor for prostatic epithelia [47]. Insulin also down-regulates levels of IGF-1 binding protein-1 [48], which increases bioavailability of IGF-1. Indeed, it has been suggested that IGF-1 plays an important role in carcinogenesis [49]. In addition, prostate epithelial cells have IGF-1 receptors, and IGF-1 stimulates mitogenicity in a dosedependent manner in prostate cell lines [50, 51, 52].

The inverse association between diabetes and prostate cancer may also be a result of alterations in sex hormone levels in diabetic patients. Cell division in the prostate gland is controlled by testosterone, and early prostate cancer is sensitive to androgens [53]. Prostate cancer occurs rarely in castrated men [54] and the prolonged administration of high levels of testosterone induces prostate cancer in rats $[55,56]$. $\mathrm{Pa}$ tients with cirrhosis, characterised by high oestrogen and low testosterone levels, also appear to be at lower risk of prostate cancer [57]. High testosterone levels have also been associated with an increased risk of prostate cancer [58]. Diabetic men have lower total and free testosterone levels $[59,60,61,62,63,64$, 65]. Several studies have demonstrated a stepwise decrease in mean testosterone level per progressive increase in fasting plasma glucose throughout the whole range of plasma glucose $[60,62,63]$. In laboratory animals, diabetes has been associated with reductions in testicular Leydig cell number $[66,67,68]$ and in testosterone secretion $[68,69]$, possibly due to a direct adverse effect of glycaemia [68].

In conclusion, the findings of our meta-analysis provide strong evidence of an inverse association between diabetes and prostate cancer. Future research should re-assess this association, by analysing Type 1 and Type 2 diabetes mellitus separately and taking into account the possible biases that might have affected this meta-analysis. 
Acknowledgements. No outside funding was provided for this analysis. No conflict of interest existed for any of the authors.

\section{References}

1. Everhart J, Wright D (1995) Diabetes mellitus as a risk factor for pancreatic cancer. A meta-analysis. JAMA 273: 1605-1609

2. Lagergren J, Bergstrom R, Nyren O (1999) Association between body mass and adenocarcinoma of the esophagus and gastric cardia. Ann Intern Med 130:883-890

3. Strickler HD, Wylie-Rosett J, Rohan T et al. (2001) The relation of type 2 diabetes and cancer. Diabetes Technol Ther 3:263-274

4. La Vecchia C, Negri E, D’Avango B, Boyle P, Franceschi S (1990) Medical history and primary liver cancer. Cancer Res 50:6274-6277

5. Greenland S (1994) Invited commentary: a critical look at some popular meta-analytic methods. Am J Epidemiol 140:290-296

6. Juni P, Witschi A, Bloch R, Egger M (1999) The hazards of scoring the quality of clinical trials for meta-analysis. JAMA 282:1054-1060

7. Stroup DF, Berlin JA, Morton SC et al. (2000) Meta-analysis of observational studies in epidemiology: a proposal for reporting. Meta-analysis of Observational studies in Epidemiology (MOOSE) Group. JAMA 283:2008-2012

8. Hasselblad V, Eddy DM, Kotchmar DJ (1992) Synthesis of environmental evidence. J Air Waste Manag Assoc 42: 662-671

9. Friedenreich CM, Brant RF, Riboli E (1994) Influence of methodologic factors in a pooled analysis of 13 case-control studies of colorectal cancer and dietary fiber. Epidemiology 5:66-67

10. Mantel N, Haenszel W (1959) Statistical aspects of the analysis of data from retrospective studies of disease. J Natl Cancer Inst 22:719-748

11. DerSimonian R, Laird N (1986) Meta-analysis in clinical trials. Control Clin Trials 7:177-188

12. Begg CB, Mazumdar M (1994) Operating characteristics of a rank correlation test for publication bias. Biometrics 50:1088-1101

13. Egger M, Smith GD, Schneider M, Minder C (1997) Bias in meta-analysis detected by a simple graphical test. BMJ 315:629-634

14. Cochran WG (1954) The combination of estimates from different experiments. Biometrics 8:101-129

15. Tobias A (1999) Assessing the influence of a single study in the meta-analysis estimate. Stata Tech Bull 8:15-17

16. Wilson EB, Maher HC (1932) Cancer and tuberculosis with some comments on cancer and other diseases. Am J Cancer 16:227-250

17. Glicksman AS, Rawson RW (1956) Diabetes and altered carbohydrate metabolism in patients with cancer. Cancer 91:127-134

18. Bell ET (1957) Carcinoma of pancreas. I. Clinical and pathologic study of 600 necropsied cases. II. Relation of carcinoma of pancreas to diabetes mellitus. Am J Pathol 33:499-523

19. Lancaster HO, Maddox JK (1958) Diabetic mortality in Australia. Australas Ann Med 7:145-150

20. Steele JM, Sperling WL (1961) Relationship between diabetes mellitus and cancer: a study of the records for eight years at the Robert Packer Hospital. Guthr Clin Bull 30:63-67

21. Kessler II (1970) Cancer mortality among diabetics. J Natl Cancer Inst 44:673-686
22. Henderson BE, Bogdanoff E, Gerkins VR, SooHoo J, Arthur M (1974) Evaluation of cancer risk factors in a retirement community. Cancer Res 34:1045-1048

23. O'Mara BA, Byers T, Schoenfeld E (1985) Diabetes mellitus and cancer risk: a multisite case-control study. J Chronic Dis 38:435-441

24. Adami HO, McLaughlin J, Ekbom A et al. (1991) Cancer risk in patients with diabetes mellitus. Cancer Causes Control 2:307-314

25. Talamini R, Franceschi S, La Vecchia C, Serraino D, Barra S, Negri E (1992) Diet and prostatic cancer: a case-control study in northern Italy. Nutr Cancer 18:277-286

26. Hsieh CC, Thanos A, Mitropoulos D, Deliveliotis C, Mantzoros CS, Trichopoulos D (1999) Risk factors for prostate cancer: a case-control study in Greece. Int J Cancer 80:699-703

27. Rosenberg DJ, Neugut AI, Ahsan H, Shea S (2002) Diabetes mellitus and the risk of prostate cancer. Cancer Invest 20:157-165

28. Tavani A, Gallus S, Bosetti C et al. (2002) Diabetes and the risk of prostate cancer. Eur J Cancer Prev 11:125-128

29. Weiderpass E, Ye W, Vainio H, Kaaks R, Adami HO (2002) Reduced risk of prostate cancer among patients with diabetes mellitus. Int J Cancer 102:258-261

30. Will JC, Vinicor F, Calle EE (1999) Is diabetes mellitus associated with prostate cancer incidence and survival? Epidemiology 10:313-318

31. Giovannucci E, Rimm EB, Stampfer MJ, Colditz GA, Willett WC (1998) Diabetes mellitus and risk of prostate cancer (United States). Cancer Causes Control 9:3-9

32. Wideroff L, Gridley G, Mellemkjaer L et al. (1997) Cancer incidence in a population-based cohort of patients hospitalized with diabetes mellitus in Denmark. J Natl Cancer Inst 89:1360-1365

33. Coughlin SS, Neaton JD, Sengupta A (1996) Cigarette smoking as a predictor of death from prostate cancer in 348,874 men screened for the Multiple Risk Factor Intervention Trial. Am J Epidemiol 143:1002-1006

34. Steenland K, Nowlin S, Palu S (1995) Cancer incidence in the National Health and Nutrition Survey I. Follow-up data: diabetes, cholesterol, pulse and physical activity. Cancer Epidemiol Biomarkers Prev 4:807-811

35. La Vecchia C, Negri E, Franceschi S, D’Avanzo B, Boyle P (1994) A case-control study of diabetes mellitus and cancer risk. Br J Cancer 70:950-953

36. Smith GD, Egger M, Shipley MJ, Marmot MG (1992) Post-challenge glucose concentration, impaired glucose tolerance, diabetes, and cancer mortality in men. Am J Epidemiol 136:1110-1114

37. Thompson MM, Garland C, Barrett-Connor E, Khaw KT, Friedlander NJ, Wingard DL (1989) Heart disease risk factors, diabetes, and prostatic cancer in an adult community. Am J Epidemiol 129:511-517

38. Checkoway H, DiFerdinando G, Hulka BS, Mickey DD (1987) Medical, life-style, and occupational risk factors for prostate cancer. Prostate 10:79-88

39. Ragozzino M, Melton LJ 3rd, Chu CP, Palumbo PJ (1982) Subsequent cancer risk in the incidence cohort of Rochester, Minnesota, residents with diabetes mellitus. J Chronic Dis 35:13-19

40. Wynder EL, Mabuchi K, Whitmore WF Jr (1971) Epidemiology of cancer of the prostate. Cancer 28:344-360

41. Easterbrook PJ, Berlin JA, Gopalan R, Matthews DR (1991) Publication bias in research. Lancet 337:867-872

42. Simes JR (1986) Publication bias: the case for an international registry of trials. J Clin Oncol 4:1529-1541 
43. Sterling TD (1959) Publication decisions and their possible effects on inferences drawn from tests of significance or vice versa. JASA 54:30-34

44. Nomura AMY, Kolonel LN (1991) Prostate cancer: a current perspective. Epidemiol Rev 13:200-227

45. Ries LA, Hankey BF, Edwards BK (1990) Cancer statistics review, 1973-1987. NIH Publication \#90-2789. US GPO, Washington DC

46. Chodak GW, Schoenberg HW (1989) Progress and problems in screening for carcinoma of the prostate. World $\mathrm{J}$ Surg 13:60-64

47. Peehl DM, Stamey TA (1986) Serum-free growth of adult human prostatic epithelial cells. In Vitro Cell Dev Biol 22:82-90

48. Suikkari AM, Koivisto VA, Rutanen EM, Yki-Jarvinen H, Karonen SL, Seppala M (1988) Insulin regulates the serum levels of low molecular weight insulin-like growth factorbinding protein. J Clin Endocrinol Metab 66:266-272

49. LeRoith D, Baserga R, Helman L, Roberts CT Jr (1995) Insulin-like growth factors and cancer. Ann Intern Med 122:54-59

50. Cohen P, Peehl DM, Graves HC, Rosenfeld RG (1994) Biological effects of prostate specific antigen as an insulinlike growth factor binding protein-3 protease. J Endocrinol 142:407-415

51. Cohen P, Peehl DM, Lamson G, Rosenfeld RG (1991) Insulin-like growth factors (IGFs), IGF receptors, and IGFbinding proteins in primary cultures of prostate epithelial cells. J Clin Endocrinol Metab 73:401-407

52. Iwamura M, Sluss PM, Casamento JB, Cockett AT (1993) Insulin-like growth factor I: action and receptor characterization in human prostate cancer cell lines. Prostate 22:243-252

53. Coffey DS (1979) Physiological control of prostatic growth: an overview. In: Prostate cancer. International Union Against Cancer. UICC Technical Report Series, vol 48, Geneva, pp 4-23

54. Hovenanian MS, Deming CL (1948) The heterologous growth of cancer of the human prostate. Surg Gynecol Obstet 86:29-35

55. Noble RL (1977) The development of prostatic adenocarcinoma in $\mathrm{Nb}$ rats following prolonged sex hormone administration. Cancer Res 37:1929-1933
56. Pollard M, Luckert PH, Schmidt MA (1982) Induction of prostate adenocarcinomas in Lobund Wistar rats by testosterone. Prostate 3:563-568

57. Robson MC (1966) Cirrhosis and prostatic neoplasms. Geriatrics 21:150-154

58. Gann PH, Hennekens CH, Ma J, Longcope C, Stampfer MJ (1996) Prospective study of sex hormone levels and risk of prostate cancer. J Natl Cancer Inst 88:1118-1126

59. Ando S, Rubens R, Rottiers R (1984) Androgen plasma levels in male diabetics. J Endocrinol Invest 7:21-24

60. Barrett-Connor E, Khaw KT, Yen SS (1990) Endogenous sex hormone levels in older adult men with diabetes mellitus. Am J Epidemiol 132:895-901

61. Shahwan MM, Spathis GS, Fry DE, Wood PJ, Marks V (1978) Differences in pituitary and testicular function between diabetic patients on insulin and oral anti-diabetic agents. Diabetologia 15:13-17

62. Fushimi H, Horie H, Inoue T et al. (1989) Low testosterone levels in diabetic men and animals: a possible role in testicular impotence. Diabetes Res Clin Pract 6:297-301

63. Madsbad S, Gluud C, Bennett P, Krarup T (1986) Rapid changes in plasma androgens during insulin withdrawal in male type 1 (insulin-dependent) diabetics. J Endocrinol Invest 9:21-25

64. Small M, MacRury S, Beastall GH, MacCuish AC (1987) Oestradiol levels in diabetic men with and without a previous myocardial infarction. Q J Med 64:617-623

65. Barrett-Connor E (1992) Lower endogenous androgen levels and dyslipidemia in men with non-insulin-dependent diabetes mellitus. Ann Intern Med 117:807-811

66. Oksanen A (1975) Testicular lesions of streptozotocin diabetic rats. Horm Res 6:138-144

67. Hutson JC, Stocco DM, Campbell GT, Wagoner J (1983) Sertoli cell function in diabetic, insulin-treated diabetic, and semi-starved rats. Diabetes 32:112-116

68. Jackson FL, Hutson JC (1984) Altered responses to androgen in diabetic male rats. Diabetes 33:819-824

69. Murray FT, Orth J, Gunsalus G et al. (1981) The pituitarytesticular axis in the streptozotocin diabetic male rat: evidence for gonadotroph, Sertoli cell and Leydig cell dysfunction. Int J Androl 4:265-280 